\title{
Intractable intraoperative bleeding requiring platelet transfusion during emergent cholecystectomy in a patient with dual antiplatelet therapy after drug-eluting coronary stent implantation (with video)
}

\author{
Takahisa Fujikawa, Tomohiro Noda, Seiichiro Tada, Akira Tanaka
}

Department of Surgery, Kokura Memorial Hospital, Kitakyushu, Fukuoka, Japan

\section{Correspondence to} Dr Takahisa Fujikawa, fujikawa-t@kokurakinen.or.jp

\begin{tabular}{l}
\hline To cite: Fujikawa T, Noda T, \\
Tada S, et al. BMJ Case Rep \\
Published online: [please \\
include Day Month Year] \\
doi:10.1136/bcr-2013- \\
008948 \\
\hline
\end{tabular}

\section{SUMMARY}

We report a case of a 76-year-old man, receiving dual antiplatelet therapy (DAPT) with aspirin and ticlopidine for the past 6 years after implantation of drug-eluting coronary stent, developed a severe hypochondriac pain. After diagnosing severe acute cholecystitis by an enhanced CT, emergent laparotomy under continuation of DAPT was attempted. During the operation, intractable bleeding from the adhesiolysed liver surface was encountered, which required platelet transfusion. Subtotal cholecystectomy with abdominal drainage was performed, and the patient recovered without any postoperative bleeding or thromboembolic complications. Like the present case, the final decision should be made to perform platelet transfusion when life-threatening DAPT-induced intraoperative bleeding occurs during an emergent surgery, despite the elevated risk of stent thrombosis.

\section{BACKGROUND}

In non-cardiac surgery patients receiving antiplatelet therapy, especially in patients with drug-eluting coronary stent (DES) implantation, perioperative antithrombotic management is challenging and often problematic due to increased risks of postoperative bleeding or thromboembolic complications. ${ }^{1-3}$ We report a case of intractable intraoperative bleeding requiring platelet transfusion during emergent subtotal cholecystectomy in a patient with dual anti-platelet therapy (DAPT) after DES implantation.

\section{CASE PRESENTATION}

A 76-year-old Japanese man developed an increasingly severe hypochondriac pain and visited the emergency department. He had been receiving DAPT with aspirin and ticlopidine for the past 6 years after implantation of a paclitaxel-eluting stent into his left anterior descending coronary artery. Abdominal examination revealed severe tenderness and rebound tenderness in the upper abdomen. Laboratory investigations revealed severe leucocytosis and a highly elevated $\mathrm{C}$ reactive protein level, with mildly elevated liver function tests. An urgent enhanced CT scan of his abdomen was performed which demonstrated distended gallbladder with a thickened wall and pericholecystic fluid in the right anterior hepatic space (figure 1A,B). An impacted calculus in the gallbladder neck was also found, but neither biliary duct stone nor dilation of biliary duct was detected. A diagnosis of severe acute calculous cholecystitis with adjacent tissue inflammation was made.

\section{TREATMENT}

After discussing how best to manage the patient's condition and antithrombotic status in the perioperative period by surgeons, gastroenterologists, cardiologists and anaesthetists, a plan was carefully documented and forwarded to all departments involved in the patient's management. Owing to high risk of bleeding, percutaneous transhepatic gallbladder aspiration/drainage was rejected by gastroenterologists, and the decision was finally made that an emergent surgery under continuation of both aspirin and clopidogrel was a preferred choice to prevent possible life-threatening stent thrombosis. The patient was informed regarding risks and benefits, who agreed with the operation.

A surgical intervention was attempted as an emergent setting. After laparotomy, severe adhesion of the omentum and transverse colon surrounding the gallbladder and the liver was found. Adhesiolysis was carefully attempted but intractable bleeding from the adhesiolysed surface was encountered, which was barely and temporarily controlled by packing some large gauzes. Owing to severe inflammation around the neck of the gallbladder and difficulty in controlling the bleeding, we chose to perform subtotal cholecystectomy without dissecting the Calot's triangle. Only the anterior wall of the gallbladder was excised, leaving the posterior wall of the gallbladder in situ, and all gallstones were retrieved and extracted along with the excised gallbladder wall. The orifice of the cystic duct and the cavity in the neck were closed by several interrupted sutures without dissecting or dividing the cystic duct or artery. After cholecystectomy was performed, repeated haemostasis to the bleeding area of the liver was attempted by using multiple devices and methods including an electrocautery, several absorbable haemostats including a regenerated cellulose, and even a soft-coagulation system, which is a strong haemostatic device for liver resection, but the attempt failed due to intractable DAPT-induced 
Figure 1 (A and B) Multidetector enhanced CT scan of the abdomen demonstrated distended gallbladder with a thickened wall and pericholecystic fluid in the right anterior hepatic space (red arrow heads), a finding consistent with severe acute cholecystitis with adjacent tissue inflammation. An impacted calculus in the gallbladder neck was also found (red arrow in 1B). (C) After subtotal cholecystectomy was performed, haemostasis to the bleeding area of the liver was attempted but failed due to intractable dual antiplatelet therapy-induced bleeding. (D) Decision was made to perform 10 units of platelet transfusion, and prompt haemostasis was achieved.

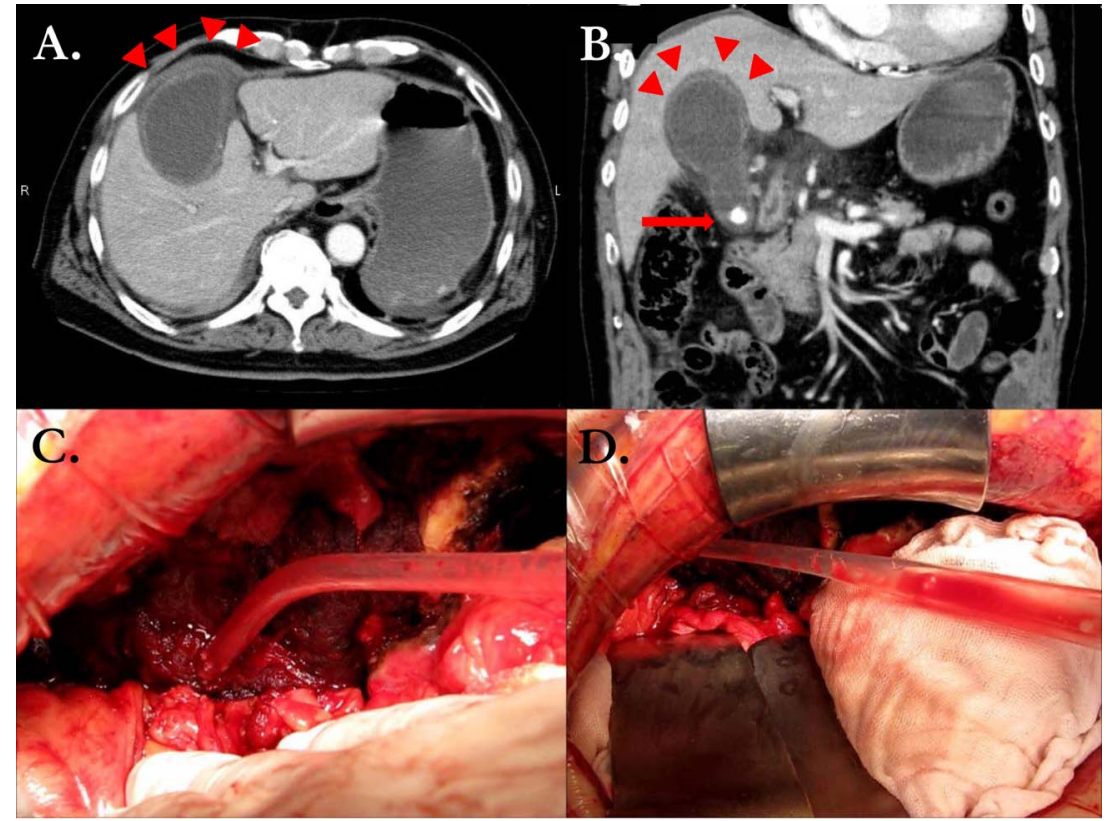

bleeding (figure 1C, video 1). Despite the elevated risk of coronary stent thrombosis, we finally decided to perform 10 units of platelet transfusion, and prompt haemostasis was achieved (figure 1D, video 2). The abdominal wall was closed and postoperative management was introduced in the intensive care unit, without any immediate critical complications.

\section{OUTCOME AND FOLLOW-UP}

The patient recovered soon postoperatively without any thromboembolic or bleeding complications (figure 2). His antiplatelet therapy was reinstituted in stages; aspirin was restarted on postoperative day (POD) 3 and ticlopidine on POD 8 . He was discharged home on POD 12.

\section{DISCUSSION}

DES has been shown to be more effective than conventional bare-metal stents in reducing angiographic restenosis, by limiting intimal hyperplasia. $^{4-6}$ On the other hand, there is growing concern that delayed endothelisation and incomplete neointimal

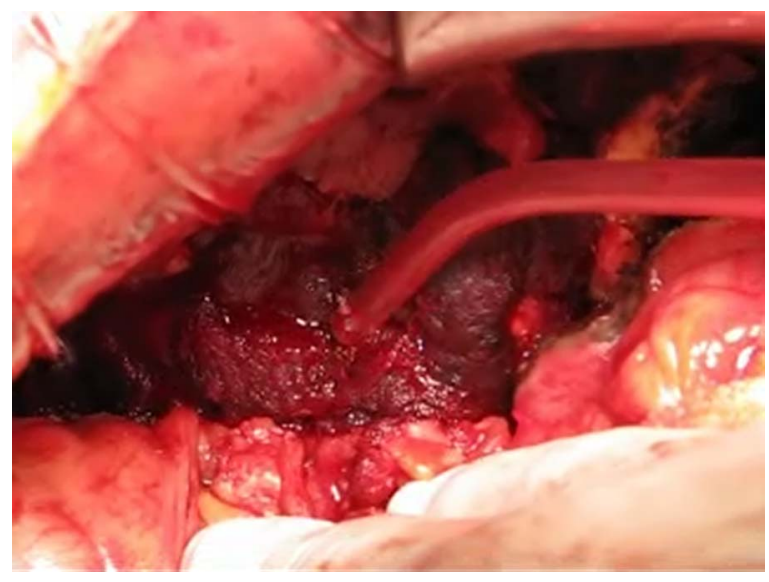

Video 1 After subtotal cholecystectomy was performed, repeated haemostasis to the bleeding area of the liver was attempted by using multiple devices and methods, but failed due to intractable dual antiplatelet therapy-induced bleeding. healing might lead to adverse cardiac outcomes and death as a result of late or very late stent thrombosis, an uncommon but life-threatening complication of stent implantation. ${ }^{7} 8$ Death rates due to stent thrombosis have ranged from $16 \%$ to as high as $45 \%$ in recently published reports. ${ }^{9} 10$ Thus, patients treated with DES implantation need long-term DAPT with aspirin and thienopiridines (clopidogrel or ticlopidine) to prevent stent thrombosis. ${ }^{11} 12$

In non-cardiac surgery patients receiving antiplatelet therapy, especially in patients with DES implantation, perioperative antithrombotic management is challenging and often problematic due to increased risks of postoperative bleeding and/or thromboembolic complications. ${ }^{1-3}$ Potential risk of vessel/stent thrombosis may increase when DAPT is stopped perioperatively, whereas surgical haemorrhage or postoperative bleeding complications may occur more often when DAPT is continued before or during the operation. ${ }^{13-16}$ Rigorous assessment and perioperative management, as well as meticulous intraoperative dissection and haemostasis, is warranted in such a complicated situation, but so far no consensus has been established

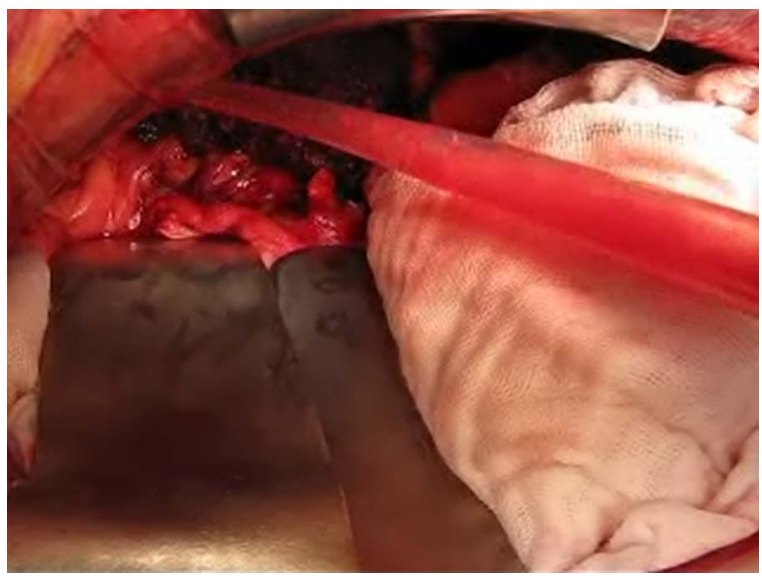

Video 2 Despite the elevated risk of coronary stent thrombosis, we finally decided to perform 10 units of platelet transfusion, and prompt haemostasis was achieved. 


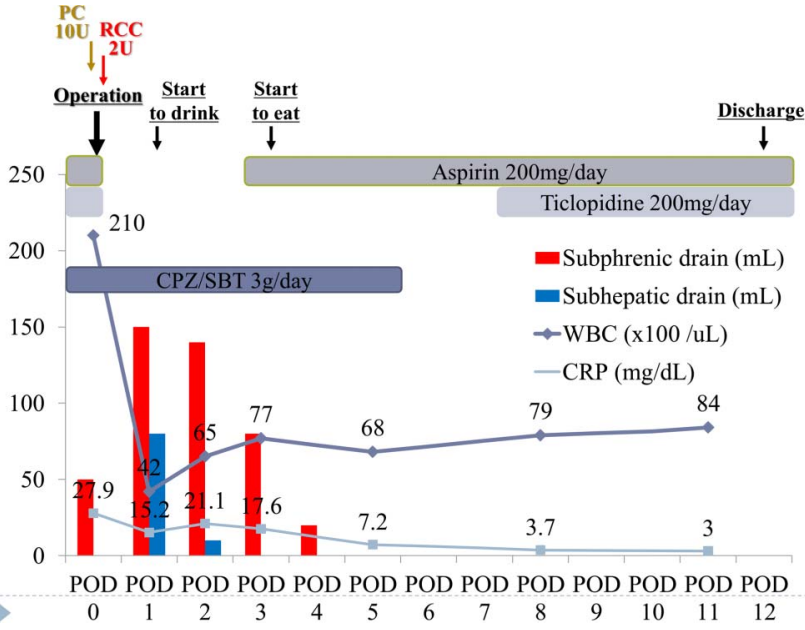

Figure 2 Postperative clinical course of the patient. During the operation, 2 units of red blood cell concentrate and 10 units of platelet concentrate was required due to intractable bleeding from the liver. The patient condition was promptly recovered postoperatively, without any thromboembolic or bleeding complications. His antiplatelet therapy was reinstituted in stages; aspirin was restarted on postoperative day (POD) 3 and ticlopidine on POD 8. RCC, red blood cell concentrate; PC, platelet concentrate; CPZ/SBT, sulbactam/cefoperazone; WBC, white blood cell count; CRP, C reactive protein.

concerning the optimal perioperative strategy in these patients for prevention of both complications. Concerning the side of bleeding risks, the consequences for patients undergoing emergent surgery with possible bleeding risks, in whom a DES has been inserted with DAPT, are serious and potentially lifethreatening, like the current case. ${ }^{2} 11{ }^{12}$ It is reported that cessation or reversal of the antiplatelet therapy increases 90 -fold relative risk of coronary thrombosis. ${ }^{9}$ However, despite the elevated risk of stent thrombosis, a final decision should be made to perform platelet transfusion when life-threatening severe intraoperative bleeding occurs.

\section{Learning points}

- Patients with dual antiplatelet therapy (DAPT) following drug-eluting coronary stent (DES) who need to undergo abdominal surgery are at extremely high-risk for both stent thrombosis and bleeding complication.

- When abdominal surgery was planned in DES-implanted patients, rigorous assessment and perioperative management, as well as meticulous intraoperative dissection and haemostasis, are requisite to achieve successful outcome.

- In some situations like the present case, a final decision should be made to perform platelet transfusion when life-threatening intraoperative DAPT-induced bleeding occurs during an emergent surgery, despite the elevated risk of stent thrombosis.
Competing interests None.

Patient consent Obtained.

Provenance and peer review Not commissioned; externally peer reviewed.

\section{REFERENCES}

1 Thachil J, Gatt A, Martlew V. Management of surgical patients receiving anticoagulation and antiplatelet agents. Br J Surg 2008;95:1437-48.

2 Fujikawa T, Maekawa $\mathrm{H}$, Shiraishi $\mathrm{K}$, et al. Successful resection of complicated bleeding arteriovenous malformation of the jejunum in patients starting dual-antiplatelet therapy just after implanting a drug-eluting coronary stent. BMJ Case Rep 2012. doi:pii: bcr2012006779. 10.1136/bcr-2012-006779

3 Mita K, Ito H, Murabayashi R, et al. Postoperative bleeding complications after gastric cancer surgery in patients receiving anticoagulation and/or antiplatelet agents. Ann Surg Oncol 2012;19:3745-52.

4 Morice MC, Serruys PW, Sousa JE, et al. A randomized comparison of a sirolimus-eluting stent with a standard stent for coronary revascularization. $N$ Eng/ $J$ Med 2002:346:1773-80.

5 Moses JW, Leon MB, Popma JJ, et al. Sirolimus-eluting stents versus standard stents in patients with stenosis in a native coronary artery. $N$ Engl J Med 2003;349:1315-23.

6 Stone GW, Ellis SG, Cannon L, et al. Comparison of a polymer-based paclitaxel-eluting stent with a bare metal stent in patients with complex coronary artery disease: a randomized controlled trial. JAMA 2005;294:1215-23.

7 Ong AT, McFadden EP, Regar E, et al. Late angiographic stent thrombosis (LAST) events with drug-eluting stents. J Am Coll Cardiol 2005;45:2088-92.

8 Nordmann AJ, Briel M, Bucher HC. Mortality in randomized controlled trials comparing drug-eluting vs. bare metal stents in coronary artery disease: a meta-analysis. Eur Heart J 2006;27:2784-814.

9 lakovou I, Schmidt T, Bonizzoni E, et al. Incidence, predictors, and outcome of thrombosis after successful implantation of drug-eluting stents. JAMA 2005;293:2126-30.

10 De la Torre-Hernandez JM, Alfonso F, Hernandez F, et al. Drug-eluting stent thrombosis: results from the multicenter Spanish registry ESTROFA (Estudio ESpanol sobre TROmbosis de stents FArmacoactivos). J Am Coll Cardiol 2008;51:986-90.

11 Eisenberg MJ. Drug-eluting stents: some bare facts. Lancet 2004;364:1466-7.

12 McFadden EP, Stabile E, Regar E, et al. Late thrombosis in drug-eluting coronary stents after discontinuation of antiplatelet therapy. Lancet 2004;364:1519-21.

13 Kaluza GL, Joseph J, Lee JR, et al. Catastrophic outcomes of noncardiac surgery soon after coronary stenting. J Am Coll Cardiol 2000;35:1288-94.

14 Wilson SH, Fasseas $\mathrm{P}$, Orford $\mathrm{JL}$, et al. Clinical outcome of patients undergoing non-cardiac surgery in the two months following coronary stenting. J Am Coll Cardiol 2003;42:234-40.

15 Nasser M, Kapeliovich M, Markiewicz W. Late thrombosis of sirolimus-eluting stents following noncardiac surgery. Catheter Cardiovasc Interv 2005;65:516-19.

16 Broad L, Lee T, Conroy M, et al. Successful management of patients with a drug-eluting coronary stent presenting for elective, non-cardiac surgery. $\mathrm{Br} \mathrm{J}$ Anaesth 2007;98:19-22. 
Copyright 2013 BMJ Publishing Group. All rights reserved. For permission to reuse any of this content visit http://group.bmj.com/group/rights-licensing/permissions.

BMJ Case Report Fellows may re-use this article for personal use and teaching without any further permission.

Become a Fellow of BMJ Case Reports today and you can:

- Submit as many cases as you like

- Enjoy fast sympathetic peer review and rapid publication of accepted articles

- Access all the published articles

- Re-use any of the published material for personal use and teaching without further permission

For information on Institutional Fellowships contact consortiasales@bmjgroup.com

Visit casereports.bmj.com for more articles like this and to become a Fellow 